\title{
Sodium Arsenite Induced Hepatotoxicity and the Ameliorative Combined Effects of Allium Sativum and Gongronema Latifolium in Rats
}

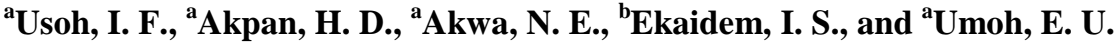 \\ ${ }^{a}$ Department of Biochemistry, Faculty of Basic Medical Sciences, University of Uyo, Uyo, Nigeria \\ ${ }^{b}$ Department of Chemical Pathology, University of Uyo Teaching Hospital, Uyo. Nigeria
}

\begin{abstract}
This study evaluates the ameliorative combined effects of Allium sativum and Gongronema latifolium in sodium arsenite induced hepatotoxicity in rats. Fifty male rats were obtained and used. They were sustained with commercial rat pellets and water. The rats were grouped into ten groups of five rats each. Group1 rats were the normal control, Group 2, 3 and 4 were treated with different durations of $10 \mathrm{mg} / \mathrm{kg}$ bw of sodium arsenite intraperitoneally, Group 5 and 6 rats were treated with $200 \mathrm{mg} / \mathrm{kg}$ bw of Gongronema latifolium and Allium sativum orally, and $10 \mathrm{mg} / \mathrm{kg}$ bw of sodium arsenite intraperitoneally, respectively. Group 7 and 8 were treated with $200 \mathrm{mg} / \mathrm{kg}$ bw of Gongronema latifolium and Allium sativum orally, respectively. Group 10 rats were treated with $100 \mathrm{mg} / \mathrm{kg}$ bw each of Gongronema latifolium and Allium sativum orally. After seven days of treatments, the rats were sacrificed and blood sample was collected for liver function indices, and also the liver for histological analysis. The results indicated that the liver of the rats treated with different durations of the toxicant suffered different degrees of damage while the single extracts and toxicant treated groups indicated minimal hepatotoxicity when compared to the toxicant only treated groups and the control group. However, the combined extract group indicated effective amelioration of the hepatotoxicity and it was revealed that the liver as a whole was not damaged. In conclusion, Allium sativum ameliorated the hepatotoxicity better than Gongronema latifolium, while the combined form showed greater restorative potential and ameliorated hepatotoxicity much better than the single extracts.
\end{abstract}

Keywords: Allium sativum; Gongronema latifolium; hepatotoxicity; rats; Sodium arsenite.

\subsection{Introduction}

Sodium arsenite is a compound containing a non -essential trace element (arsenic). It is a potent toxicant, mutagen and xenobiotic metalloid compound. It is an inorganic compound with formula $\mathrm{NaAsO}_{2}$ [1]. It is usually found in our environment through contaminated water from industrial activities and pesticides alongside other sources. Sodium arsenite can enter food chain and spread throughout the animal and plant kingdom. It has been discovered in meat and milk [2]. Exposure to this toxicant can induce oxidative stress through the generation of reactive oxygen species (ROS), vascular, peripheral disorders, skin cancer, neuropathy, multisystem organ failure, cardiovascular disorders, inflammatory and neoplastic change of respiratory and nervous system decrease in reproduction and behavioural changes [3]. Sodium arsenite toxicity mediated oxidative stress activates JNK (C-JUN- N- terminal kinase) and p38 MAPK (mitogen-activated protein kinase) and induces apoptosis in the hepatocytes [4]. Exposure to sodium arsenite toxicity leads to hepatotoxicity giving rise to increase in serum bilirubin, alanine amino transferase (ALT), aspartate amino transferase (AST) and malonaldehyde [2].

Several researches have been carried out on how to ameliorate sodium arsenite toxicity [5], but it is worthy to note that medicinal plants are cheaper and have less side- effect in coping toxicity. For this reason, Allium sativum (garlic) and Gongronema latifolium (local name 'Utazi' in Nigeria) has been used in this research. Several researches have been carried out on how to ameliorate sodium arsenite toxicity (Borek, 1998), but it is worthy to note that medicinal plants are cheaper and have less side- effect in coping toxicity.

Allium sativum is closely related to onion as they belong to the same genus. It is a bulbous plant growing up to one metre (3.3ft) in height. It is commonly used as season in food. Garlic extract has been reported to have protective effect on the liver and also plays major role in detoxification, as demonstrated in vivo from liver toxins: carbon tetrachloride, paracetamol and bromo benzene [6]. Garlic can inhibit both the formation and bioactivation of liver carcinogenic nitrosamines and can prevent the mutagenic effects of aflatoxin B1 [5].

Gongronema latifolium is a medicinal plant with broad leaves and bitter taste. This plant is common in Nigeria, Sierra Leone, Cote d' ivoire, Ghana and Senegal [7]. Some scientific researchers have proven their efficacy in IJRP 2020, 56(1), 79-97; doi:.10.47119/IJRP100561720201310 
environment should be safe and healthy for habitation. Water, soil and air basically surround the environment and should be protected from all sort of toxicity. Sodium arsenite has been identified as one of the toxic agent affecting our environment due to activities of some industries making use of this toxicant [9]. Even individuals working in these industries get exposed to this toxicant. This toxicant is capable of affecting major organs such as the liver and others, and also the cardiovascular system as a whole [10]. In response to this problem, this study seeks to remedy the hepatotoxicity created by this toxicant by the use of combined extract of Allium sativum and Gongronema latifolium owing to its efficacy in ameliorating toxicity and also its availability in our locality.

\section{1 Materials and Methods}

\section{Chemicals, reagents and equipment used}

All the chemicals, reagents and equipment used in this research were of international standard, standardized by ISO and analytical grade without any form of impurities.

\section{Collection and preparation of plant materials}

Allium sativum bulb and fresh leaves of Gongronema latifolium were purchased from Itam market, Uyo in Akwa-Ibom state. They were authenticated by the Botany Department of University of Uyo, Uyo. The Gongronema latifolium leaves were air dried for three days while the Allium sativum bulbs were cut to smaller pieces and air dried for five days at room temperature.1000g each of the dried leaves of Gongronema latifolium and Allium sativum pieces, were blended separately with KENWOOD electric blender (KENWOOD LTD. ENGLAND), and soaked in $80 \%$ ethanol for 24 hours. There after it was sieved with a WhatMan No. 1 filter paper to remove the excess ethanol. The filtrate were separately concentrated in invacuo at $37-40{ }^{\circ} \mathrm{C}$ a using a rotary evaporator. The concentrates were allowed open in a water bath at $40^{\circ} \mathrm{c}$ for complete ethanol removal. The dried extracts were refrigerated at $2-8{ }^{\circ} \mathrm{C}$ until required for use. The concentration of the extract was determined by drying a volume and measuring the dried weight.

\section{Experimental animals and grouping}

Fifty male Wistar rats (115-280g) were obtained, grouped into ten groups of five each and housed in well ventilated cages (wooden bottom and wire mesh top) and kept under controlled environmental conditions of temperature $\left(25 \pm 5^{\circ} \mathrm{C}\right)$, relative humidity $(50 \pm 5 \%)$ and twelve hour light/dark cycle in the animal house of University of Uyo, Uyo. Akwa Ibom State. The animals were fed with commercial rat pellets obtained from Uyo and also allowed free access to water.

\section{Experimental design}

Animals were randomized into ten groups of five each as in Table 1. The extracts and sodium arsenite, dissolved in distilled water were administered orally and intraperitoneally, respectively. 
Table 1: Experimental design

\begin{tabular}{|c|c|c|}
\hline Id & Group & Treatment \\
\hline $\mathrm{NC}$ & 1 & Only normal feed \\
\hline $\mathrm{SA}^{1}$ & 2 & $10 \mathrm{mg} / \mathrm{kg}$ body weight of sodium arsenite only on day 1 \\
\hline $\mathrm{SA}^{1-7}$ & 3 & $10 \mathrm{mg} / \mathrm{kg}$ body weight of sodium arsenite from day 1 to day 7 \\
\hline $\mathrm{SA}^{7}$ & 4 & $10 \mathrm{mg} / \mathrm{kg}$ body weight of sodium arsenite only on day 7 \\
\hline GLSA & 5 & $\begin{array}{l}200 \mathrm{mg} / \mathrm{kg} \text { bodyweight of Gongronema latifolium from day1 to } 6 \\
\text { and } 10 \mathrm{mg} / \mathrm{kg} \text { body weight of sodium arsenite on day } 7\end{array}$ \\
\hline ASSA & 6 & $\begin{array}{l}200 \mathrm{mg} / \mathrm{kg} \text { bodyweight of Allium sativum from day } 1 \text { to } 6 \text { and } \\
10 \mathrm{mg} / \mathrm{kg} \text { body weight of sodium arsenite on day } 7\end{array}$ \\
\hline GLASSA & 7 & $\begin{array}{l}100 \mathrm{mg} / \mathrm{kg} \text { body weight each of Allium sativum and Gongronema latifolium for } \\
6 \text { days and } 10 \mathrm{mg} / \mathrm{kg} \text { body weight of sodium arsenite only on day } 7\end{array}$ \\
\hline GL & 8 & $200 \mathrm{mg} / \mathrm{kg}$ body weight of Gongronema latifolium from day $1-7$ \\
\hline AS & 9 & $200 \mathrm{mg} / \mathrm{kg}$ body weight of Allium sativum from day $1-7$ \\
\hline GLAS & 10 & $\begin{array}{l}100 \mathrm{mg} / \mathrm{kg} \text { body weight each of Allium sativum and Gongronema latifolium for } 7 \\
\text { days }\end{array}$ \\
\hline
\end{tabular}

\section{Collection of samples for analysis}

The animals were sacrificed $24 \mathrm{hrs}$ after the last administration, by euthanizing them under chloroform vapour and sacrificed, then whole blood was collected via cardiac puncture using sterile syringes and needles and put in plain and container. Serum was separated by centrifugation (3000rpm at $4^{\circ} \mathrm{C}$ for $5 \mathrm{mins}$ ) in a centrifuge machine (model 800-1, Zeny Inc. Salt Lake, USA). The liver was harvested and rinsed in normal saline, and was preserved in $10 \%$ formalin for histological analysis.

\section{Determination of liver function test}

Rat serum Aspartate Transferase (AST) Activity (colorimetric method by Reitman and Frankel) The enzymatic reaction sequence employed in the assay of aspartate aminotransferase is as follows: AST - L-Aspartate + 2-Oxoglutarate $\rightarrow$ Oxalacetate + L-Glutamate

$\mathrm{MDH}-$ Oxalacetate $+\mathrm{NADH}+\mathrm{H}+\rightarrow$ Malate $+\mathrm{NAD}++\mathrm{H}_{2} \mathrm{O}$

AST catalyzes the transfer of an amino group between L-aspartate and 2-oxoglutarate. The oxalacetate formed in the first reaction is then reacted with NADH in the presence of malate dehydrogenase (MDH) to form NAD. AST activity is determined by measuring the rate of oxidation of NADH at $550 \mathrm{~nm}$. Lactate dehydrogenase is included in the reagent to convert endogenous pyruvate in the sample to lactate during the lag phase prior to measurement [11].

\section{Rat serum Alanine Aminotransferase (ALT) Activity (colorimetric method by Reitman and Frankel)}

L-Alanine $+\alpha$-ketoglutarate $\rightarrow$ Pyruvate + Glutamate

H+pyruvate $+2,4$ - DNPH-ine $\rightarrow$ Pyruvate $+2,4$-DNPH-one 
ALT catalyzes L- alanine and $\alpha$ - ketoglutarate to form pyruvate and glutamate. The pyruvate is then reacted with 2, 4-Dinitrophenyl hydrazine (2,4-DNPH-ine) to form 2,4- DNPH-one. The addition of sodium hydroxide dissolves this complex and allows 2, 4-DNPH-one to be measured at 550nm [11].

\section{Rat serum Alkaline Phosphatase (ALP) Activity (colorimetric method)}

The enzymatic sequence employed in the assay of Alkaline Phosphatase is as follows:

Alk. Phos.

p-Npp $+\mathrm{H}_{2} \mathrm{O}$--------------> p-Nitrophenol $+\mathrm{H}_{3} \mathrm{PO}_{4}$

p-Npp is colourless but p-Nitrophenol has strong absorbance at $405 \mathrm{~nm}$. The rate of increased absorbance at 405 $\mathrm{nm}$ is proportional to the enzyme activity [12].

\section{Histological analysis}

The livers were carefully dissected out, trimmed of all fat and blotted dry to remove any blood. They were weighed and volume determined by water displacement and then fixed in $10 \%$ formal saline (fixation). The fixed tissues were transferred to a graded series of ethanol (dehydration). On day 1, they were placed in $70 \%$ alcohol for 7 hours, then transferred to $90 \%$ alcohol and left in the latter overnight. On day 2, the tissues were passed through three changes of absolute alcohol for an hour each, and then cleared in xylene (clearing). Once cleared, the tissues were infiltrated in molten paraffin wax in the oven at $58^{\circ} \mathrm{C}$. Three changes of molten paraffin wax (impregnation) at one-hour intervals were made, after which the tissues were embedded (embedding) in wax and blocked out. Prior to embedding, it was ensured that the mounted sections to be cut by the rotary microtome were oriented perpendicularly to the long axis of the tissues. The sections were designated "vertical sections". Serial sections of $5 \mu \mathrm{m}$ thick were obtained from a solid block of tissue (microtomy) fixed on clean albuminized slides to prevent sections from pulling off the slides and later stained with haematoxylin and eosin staining techniques, after which they were passed through grades of alcohol, cleared in xylene and mounted in DPX (Distyrene - Plasticizer and xylene) mountant and observed under digital light microscope [13].

\section{Statistical analysis}

All values were expressed as mean \pm standard deviation (SD) of five animals in a group. The test of significance between two groups was estimated by student's t-test with P-values $<0.05$ considered statistically significant. 


\subsection{Results and Discussion}

Table 2: Effect of combined extract of Allium sativum and Gongronema latifolium on liver function of sodium arsenite induced toxicity in rats

\begin{tabular}{|c|c|c|c|c|}
\hline Group & Id & $\operatorname{ALP}(\mathbf{U} / \mathbf{L})$ & ALT( U/L) & $\operatorname{AST}(\mathrm{U} / \mathrm{L})$ \\
\hline 1 & $\mathrm{NC}$ & $67 \pm 9.772^{\mathrm{abc}}$ & $33.2 \pm 5.809^{\mathrm{abc}}$ & $90.8 \pm 7.395^{\text {abcd }}$ \\
\hline 2 & $\mathrm{SA}^{1}$ & $150.2 \pm 17.123^{* a d}$ & $61.8 \pm 4.438^{*^{\mathrm{ad}}}$ & $218.2 \pm 25.791^{* a d}$ \\
\hline 3 & $\mathrm{SA}^{1-7}$ & $194 \pm 7.211 * \mathrm{bcd}$ & $87.3 \pm 10.066^{* \mathrm{bcd}}$ & $292 \pm 59.016^{* b c d}$ \\
\hline 4 & $\mathrm{SA}^{7}$ & $155 \pm 4.966^{* \mathrm{ad}}$ & $66 \pm 21.802 *$ ad & $214.2 \pm 9.0691^{* a d}$ \\
\hline 5 & GLSA & $148 \pm 8.124^{* a d}$ & $40.25 \pm 1.258^{* a \mathrm{acd}}$ & $177.75 \pm 13.961 *^{\text {abcd }}$ \\
\hline 6 & ASSA & $105.4 \pm 6.304 *$ abcd & $35.6 \pm 6.804^{\mathrm{abc}}$ & $91.4 \pm 9.633^{\mathrm{abc}}$ \\
\hline 7 & GLASSA & $75.75 \pm 8.261^{\mathrm{abc}}$ & $27 \pm 5.4772^{\mathrm{abc}}$ & $79.75 \pm 10.045^{* \mathrm{abc}}$ \\
\hline 8 & GL & $134.75 \pm 9.912 *$ abcd & $40.25 \pm 3.774^{\mathrm{abcd}}$ & $164.25 \pm 18.99 * \mathrm{abcd}$ \\
\hline 9 & AS & $27.2 \pm 3.114^{* \mathrm{abcd}}$ & $25.6 \pm 6.348^{\mathrm{abc}}$ & $123 \pm 20.639 *$ abcd \\
\hline 10 & GLAS & $83.0 \pm 8.438^{* a b c}$ & $33.4 \pm 4.28^{\mathrm{abc}}$ & $95.6 \pm 7.569^{\mathrm{abcd}}$ \\
\hline
\end{tabular}

Values are expressed as Mean $\pm \mathrm{SD}, *=\mathrm{p}<0.05$ vs normal control (group1); a $=\mathrm{p}<0.05 \mathrm{vs} \mathrm{SA}{ }^{1-7}$ (group 3 ); $\mathrm{b}=\mathrm{p}<0.05 \mathrm{vS} \mathrm{SA}^{7}$ (group 4); $\mathrm{c}=\mathrm{p}<0.05 \mathrm{vs} \mathrm{SA}^{1}$ (group 2), $\mathrm{d}=\mathrm{p}<0.05 \mathrm{vs}$ GLASSA (group 7)

Table 2 shows significant increase $(\mathrm{P}<0.05)$ in all the liver enzymes in Group 2, 3, 4 and 5, when compared to the control group (Group 1). Group 6 and 10 had significant increase in ALP activity only, when compared to Group 1. Group 7 had a significant reduction in AST activity when compared to the control group (Group 1). Group 8 also had a significant increase in ALP and AST activity when compared to Group 1 (the control group). Group 9 had a significantly reduced ALP and significantly raised AST activity when compared to the control group (1).

The table also shows that all the groups had significantly reduced activity in all the liver parameter when compared to Group 3.

In comparison with Group 4 animals, it was observed that for ALP, Group 3 animals had significantly increased activity, while Group 2 and 5 showed no significant difference and all other groups had significantly lowered activities. ALT and AST was significantly lower in all the groups except Group 2 which showed no significant difference when compared to the Group 4

In comparison with Group 2, it was observed that ALP was significantly increased in group 3 animals, while there was no significant difference in Group 4 and Group 5. All other groups had significantly lower activity in the ALP. ALT was significantly increased in Group 3 while Group 4 had similar activity level with the Group 2. All other groups had significantly lower activity of the ALT. For AST, Group 4 was similar to the Group 2 animals, while other groups had significantly lowered activity level.

In comparison with Group7 animals, it was observed that for ALP, significantly increased activity was seen in all the groups except Group 1and 10. ALT was significantly increased in Group 2, 3, 4, 5 and 8, while other groups were not statistically different. AST was significantly increased in all the groups except Group 6, which had no significant difference when compared with Group 7. 


\section{Histopathology of the Liver}

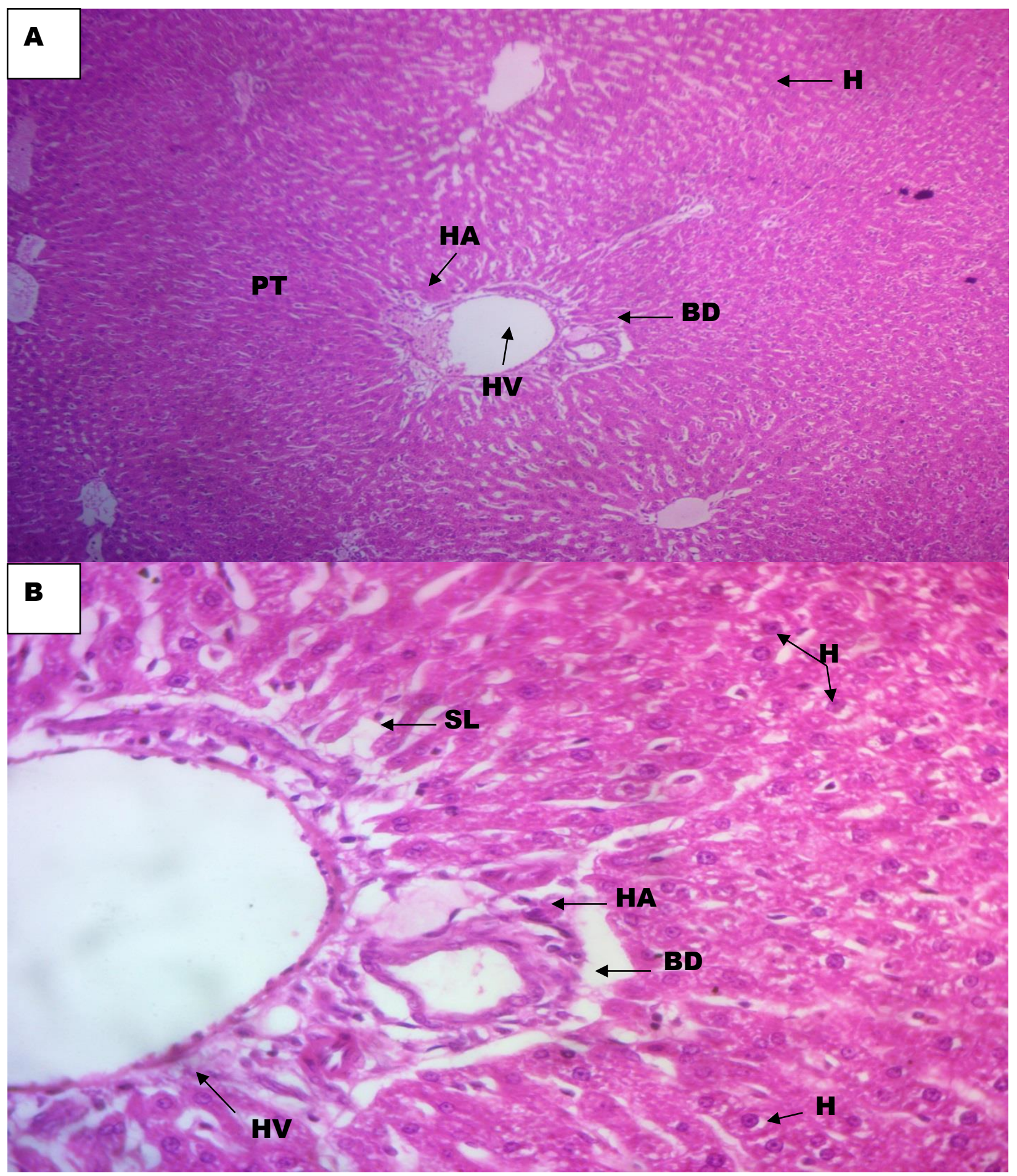

Figure 1: Photomicrographs of Control liver (Group1) stained with H \& E method at Mag. A(X100) and B(X400).

Keys: Portal Triad (PT), Hepatic Artery (HA), Hepatic Vein (HV), Bile duct (BD), Hepatocytes (H) and Sinusoid Lining (SL) 


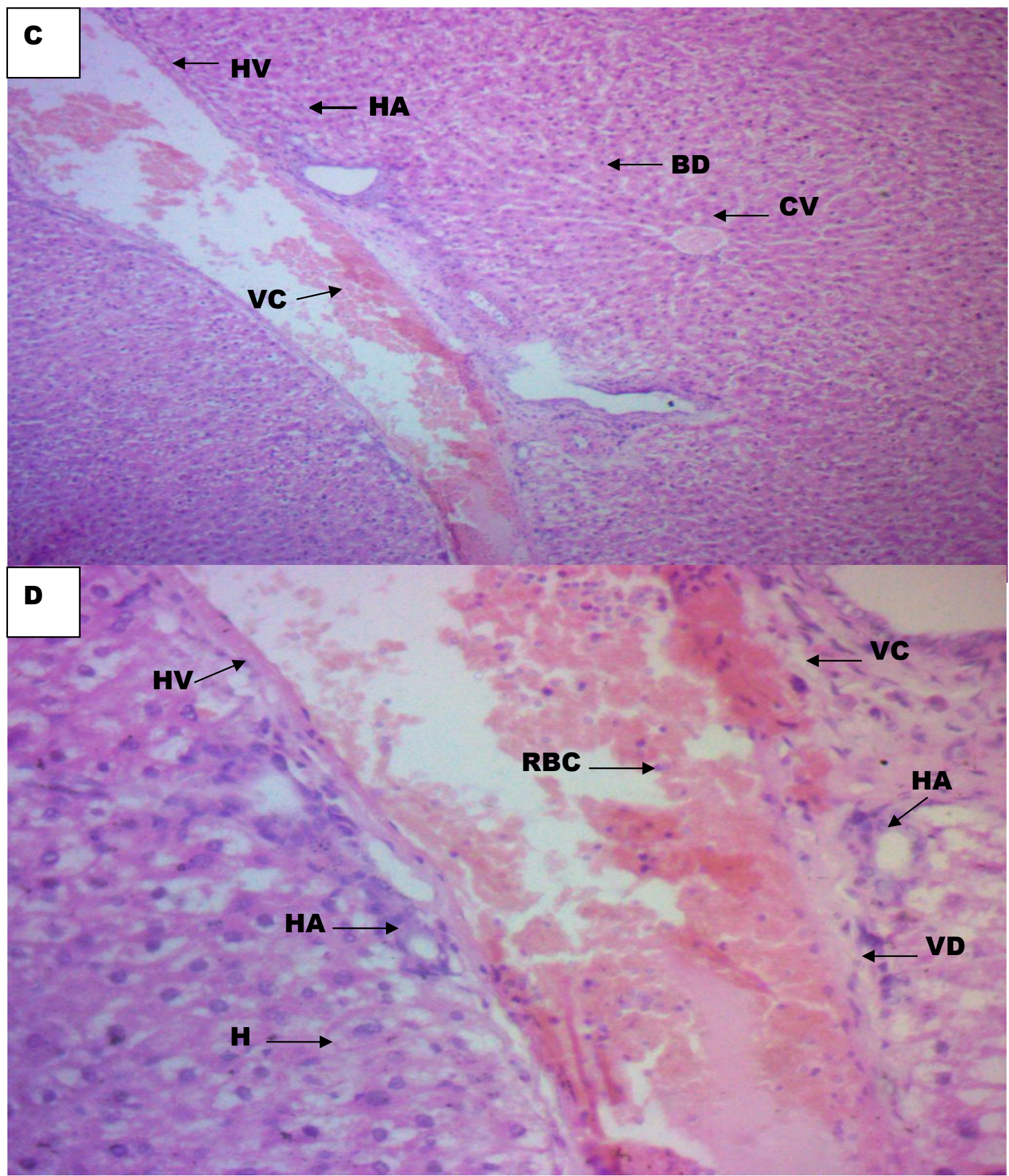

Figure 2: Photomicrographs of liver of Group 2 rats stained with $\mathrm{H}$ and E method at Mag. C(X100) and D(X400).

Keys: Portal Triad (PT), Hepatic Artery (HA), Hepatic Vein (HV), Bile duct (BD), Hepatocytes (H).Red Blood Cells (RBC) Vascular congestion (VC), Central Vein (CV) Vascular degeneration (VD) and Sinusoid Lining (SL) 


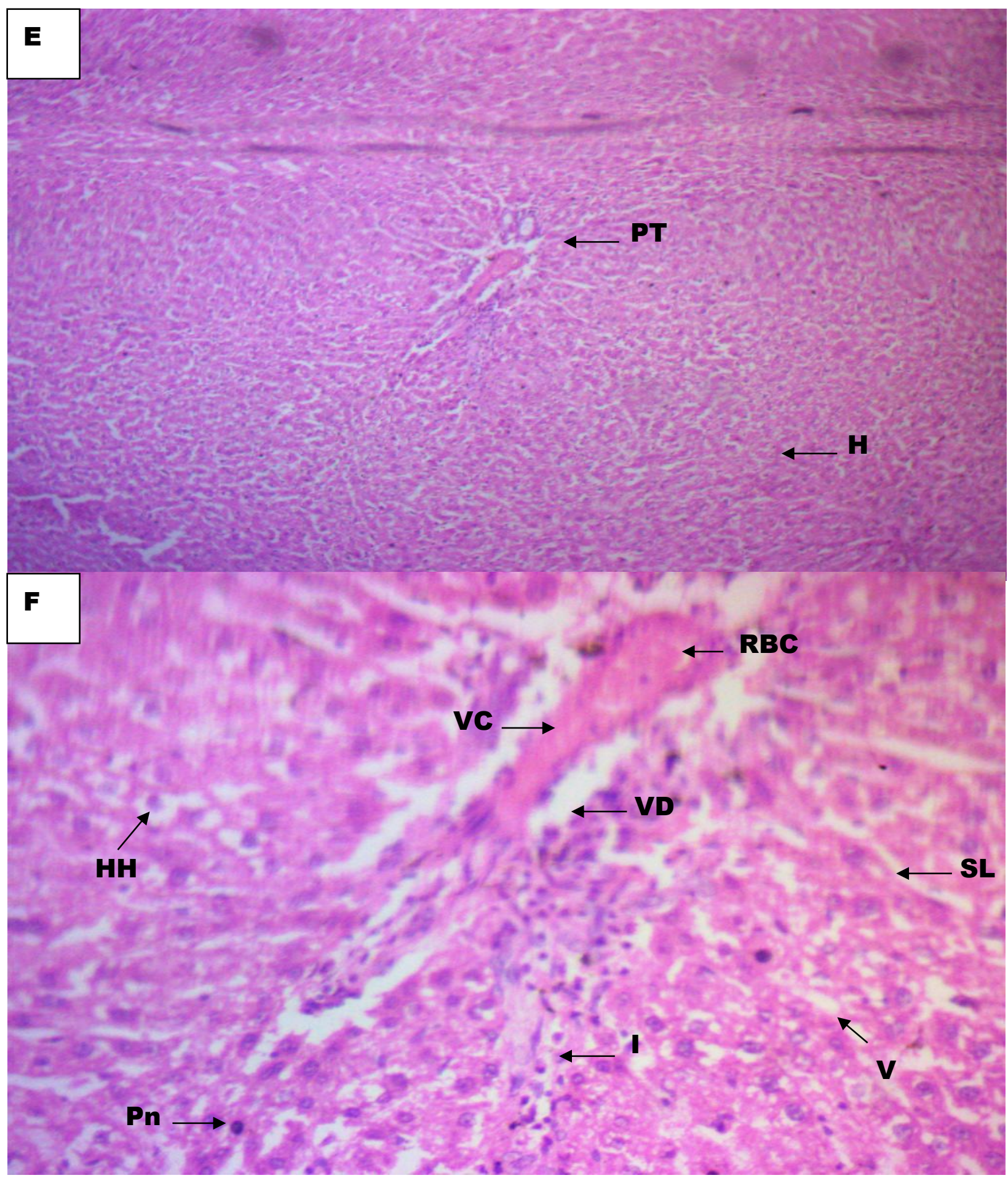

Figure 3: Photomicrographs of liver of Group 3 rats stained with $\mathrm{H}$ and E method at Mag. E(X100) and F(X400).

Keys: Portal Triad (PT), Hepatic Artery (HA), Hepatic Vein (HV), Bile duct (BD), Hepatocytes (H). Red Blood Cells (RBC) Vascular congestion (VC), Central Vein (CV) Vascular degeneration (VD), Vacuolation (V), Pyknotic Nucleus (Pn) Hepatocytic hyperplasia(Hh) and Sinusoid Lining (SL) 


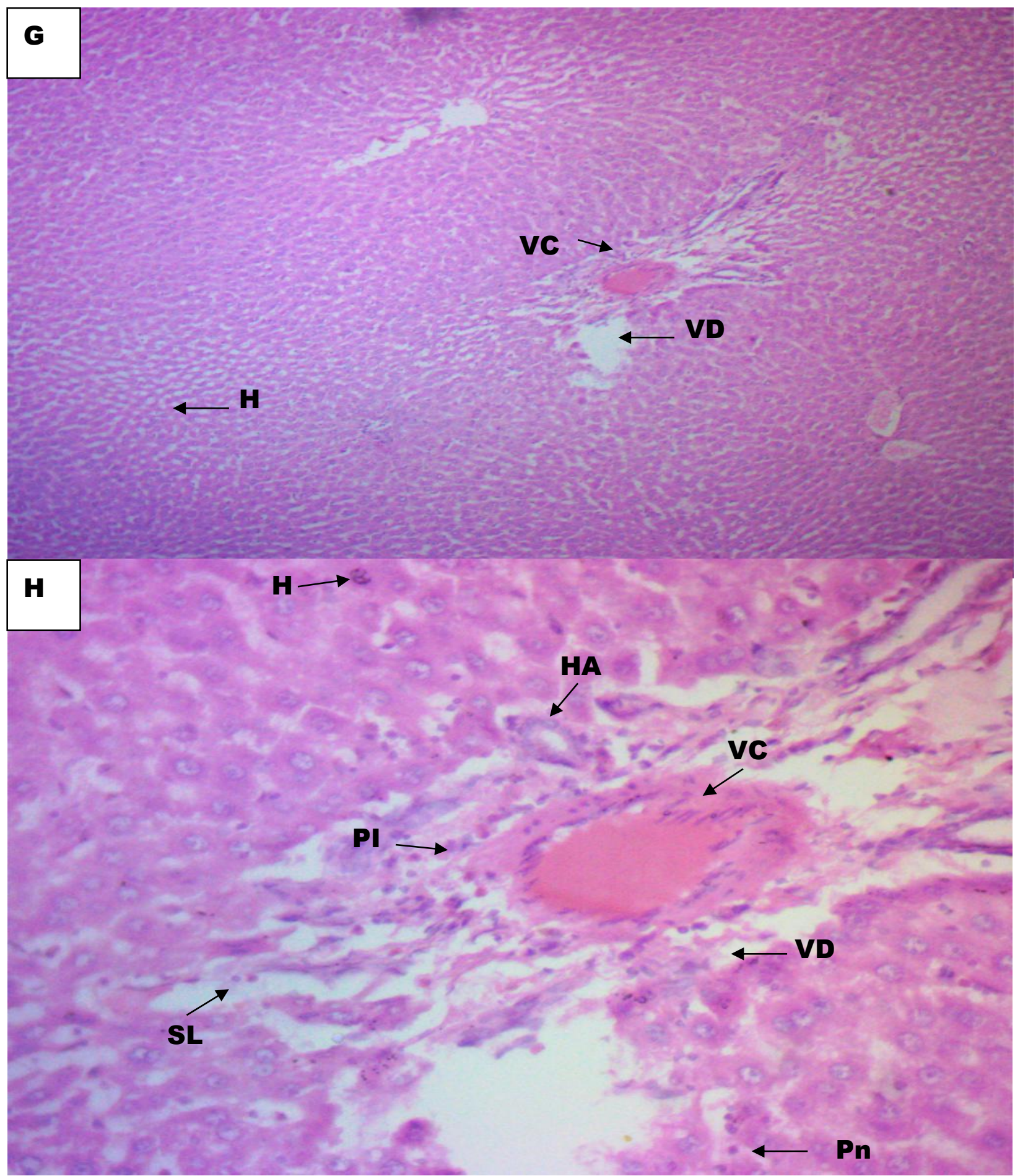

Figure 4: Photomicrographs of liver of Group 4 rats stained with $\mathrm{H}$ and E method at Mag. G(X100) and H(X400).

Keys: Portal Triad (PT), Hepatic Artery (HA), Hepatic Vein (HV), Bile duct (BD), Red Blood Cells (RBC) Vascular congestion (VC), Central Vein (CV) Vascular degeneration (VD) Pyknotic Nucleus (Pn) Hepatocytic hyperplasia (Hh) and Sinusoid Lining (SL) 


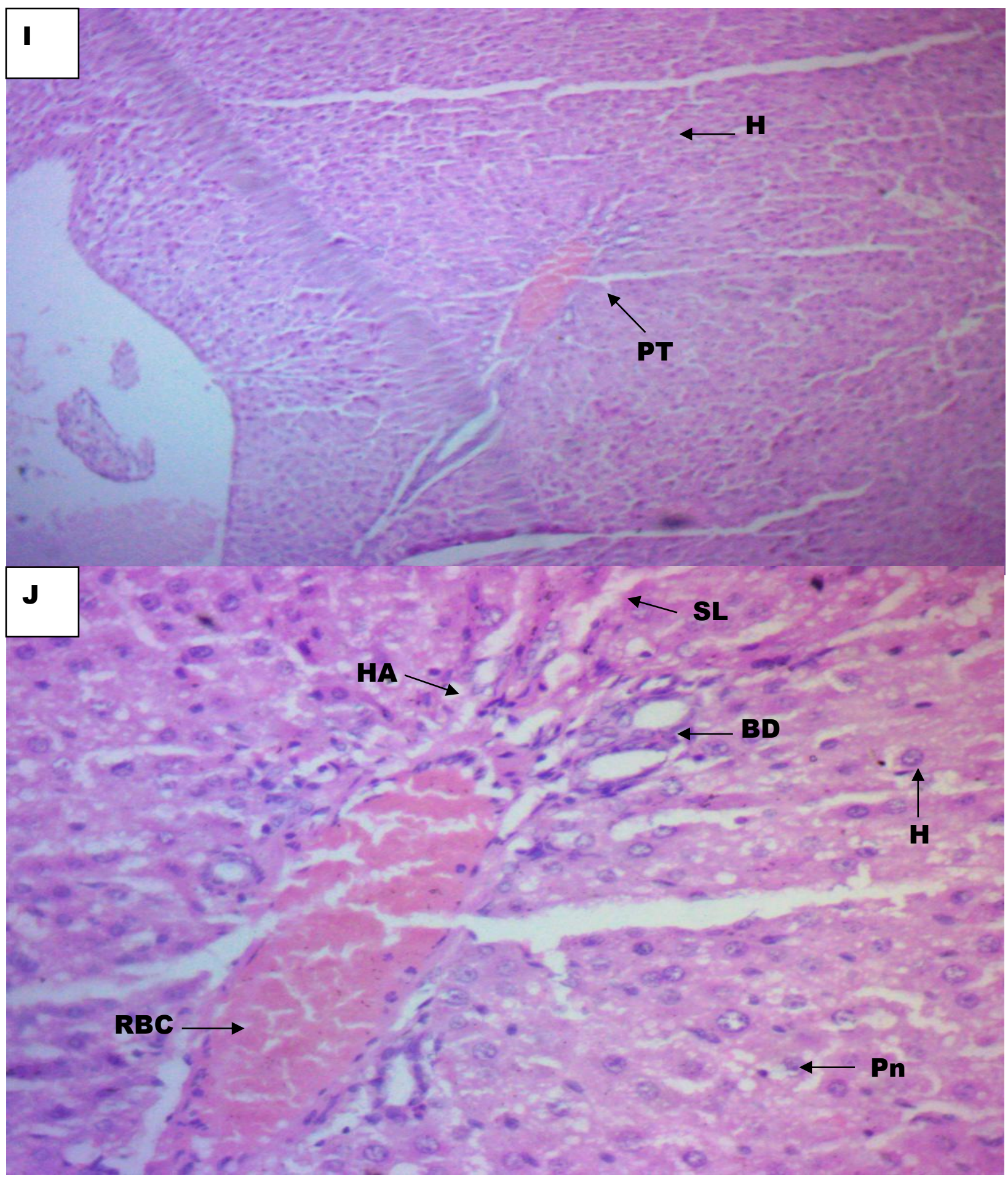

Figure 5: Photomicrographs of liver of Group 5 rats stained with H and E method at Mag. I (X100) and J (X400).

Keys: Portal Triad (PT), Hepatic Artery (HA), Hepatic Vein (HV), Bile duct (BD), Red Blood Cells (RBC), Hepatocytes (H), and Sinusoid Lining (SL), Pyknotic Nucleus (Pn) 


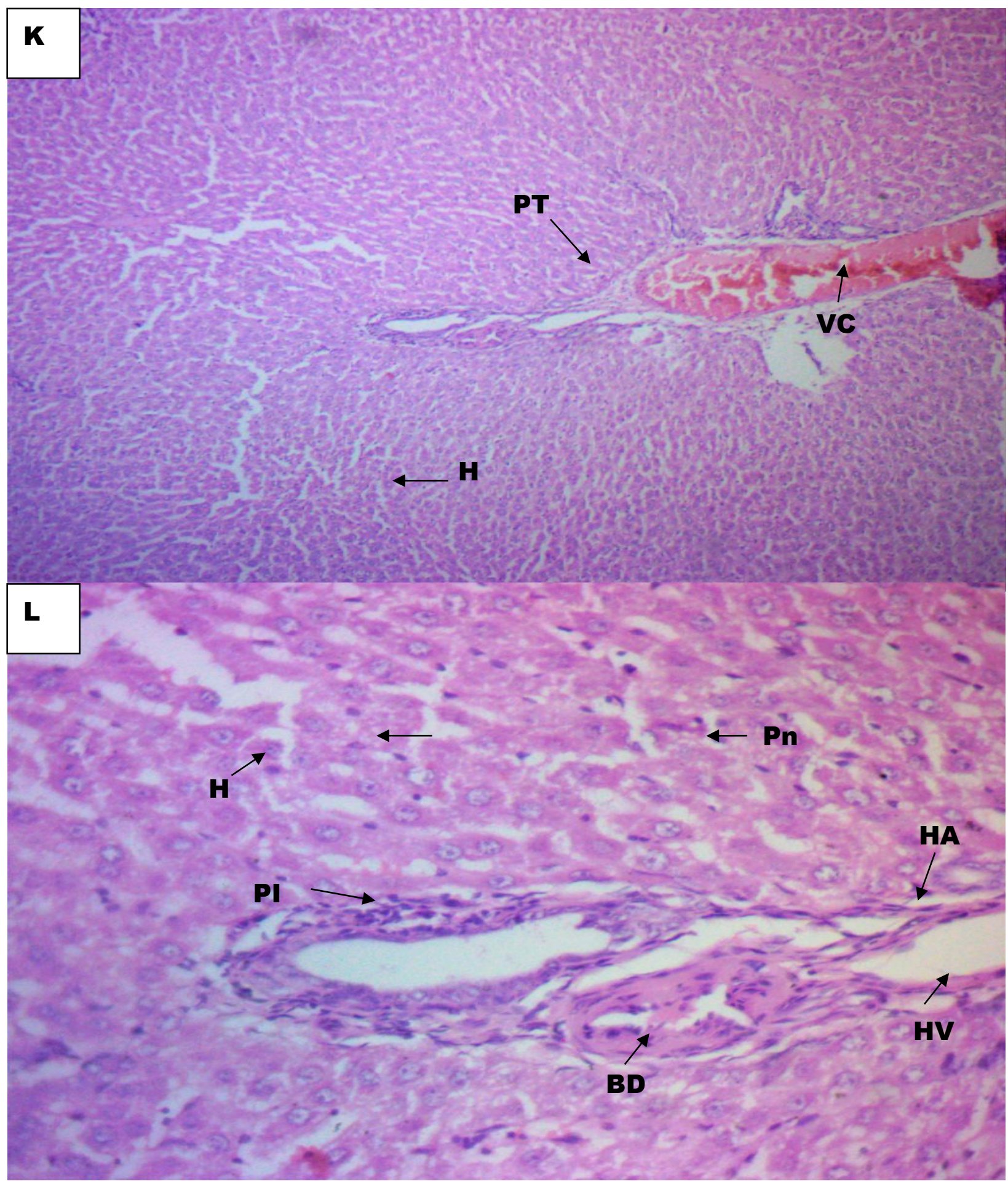

Figure 6: Photomicrographs of liver of Group 6 rats stained with H and E method at Mag. I (X100) and J (X400).

Keys: Portal Triad (PT), Hepatic Artery (HA), Hepatic Vein (HV), Bile duct (BD), Proximal Hepatocytes (H). Red Blood Cells (RBC) Vascular congestion (VC), Central Vein (CV) Vascular degeneration (VD) Pyknotic Nucleus (Pn) and Sinusoid Lining (SL) 


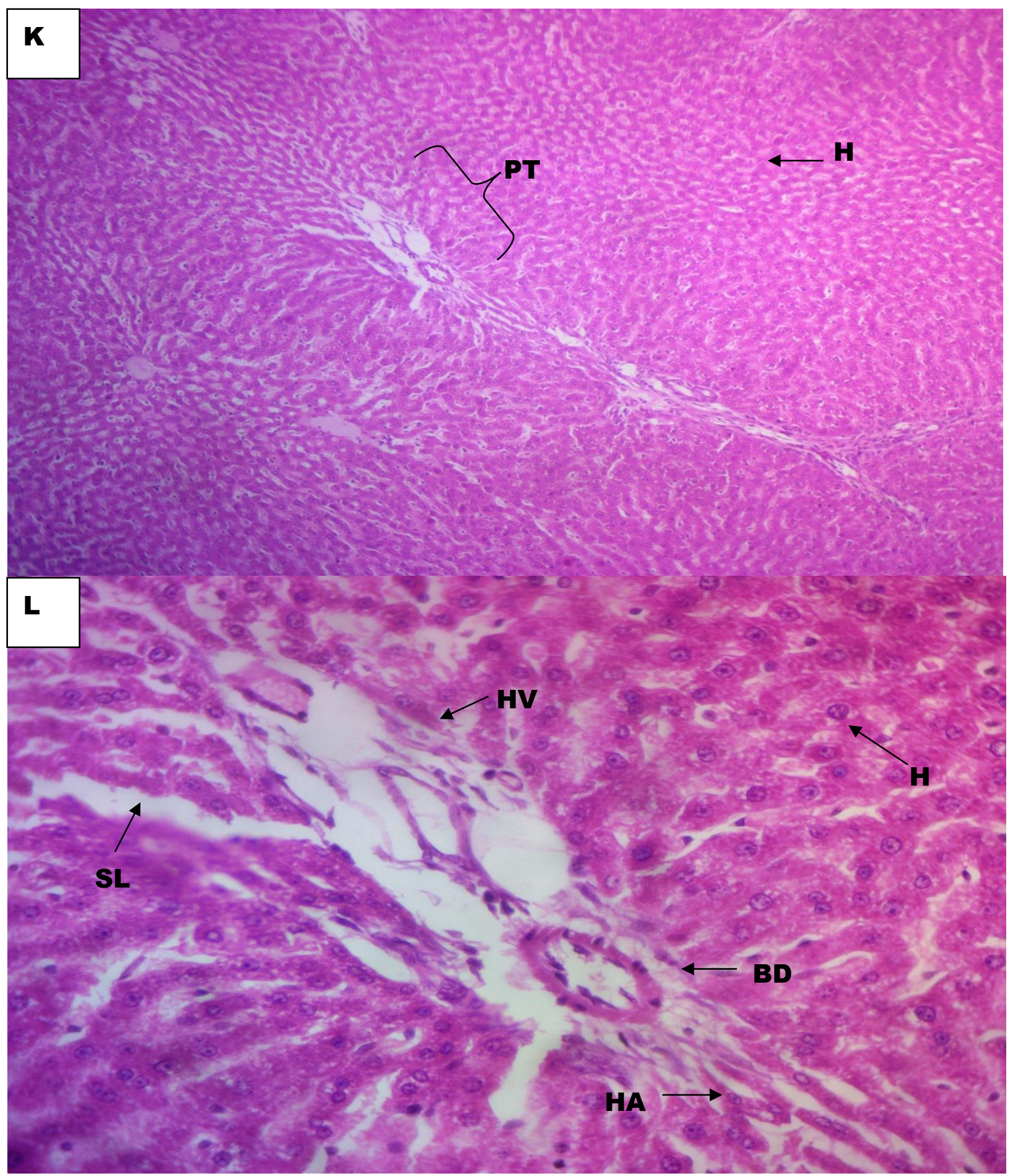

Figure 7: Photomicrographs of liver of Group 7 rats stained with H and E method at Mag. K(X100) and L(X400).

Keys: Portal Triad (PT), Hepatic Artery (HA), Hepatic Vein (HV), Bile duct (BD), Proximal Hepatocytes (H). and Sinusoid Lining (SL) 


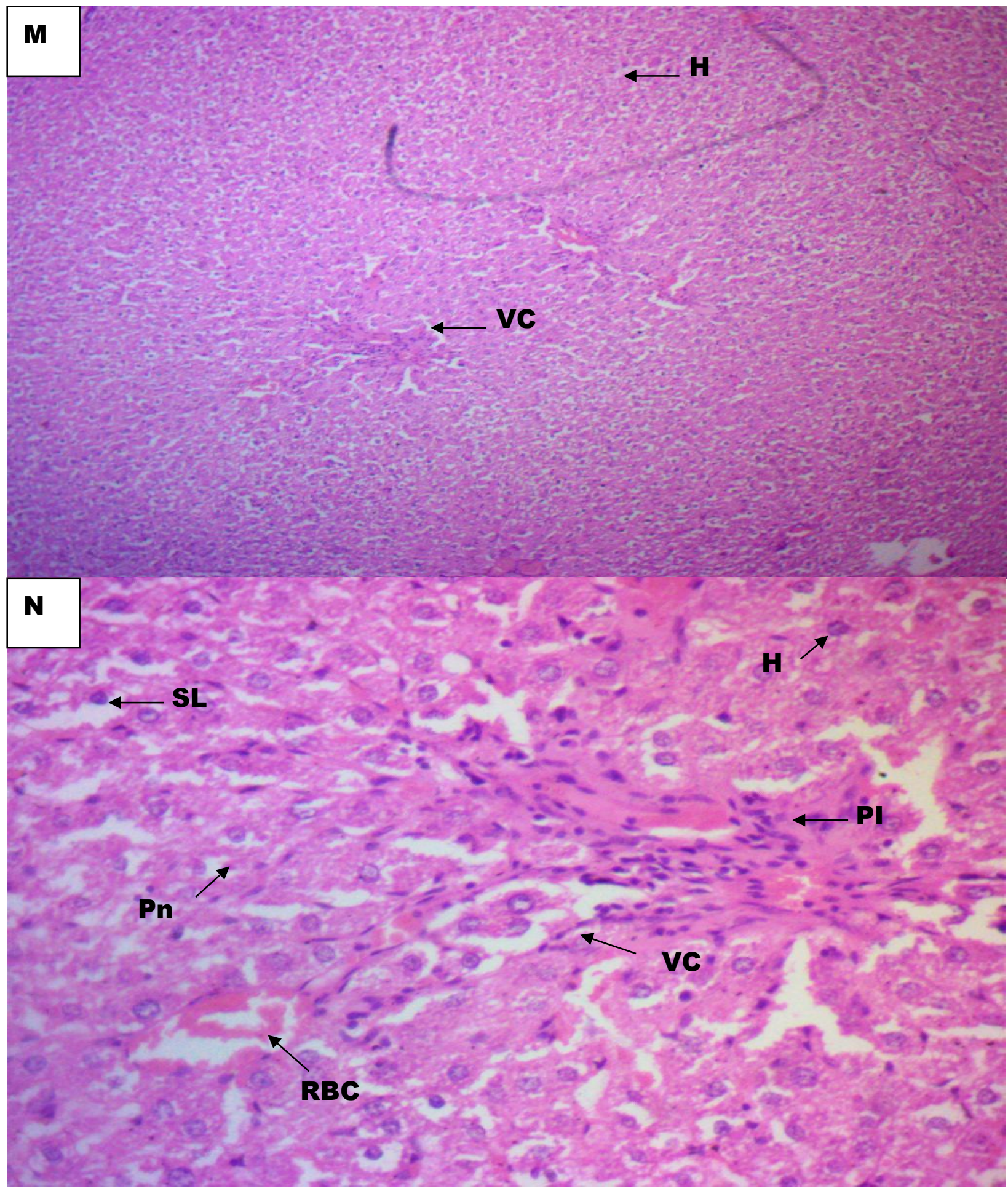

Figure 8: Photomicrographs of liver of Group 8 rats stained with H and E method at Mag. M (X100 ) and N(X400).

Keys: Portal Triad (PT), Hepatic Artery (HA), Hepatic Vein (HV), Bile duct (BD), Red Blood Cells (RBC), Hepatocytes (H). Vascular congestion (VC), Pyknotic nucleus (Pn) and Sinusoid Lining (SL) 


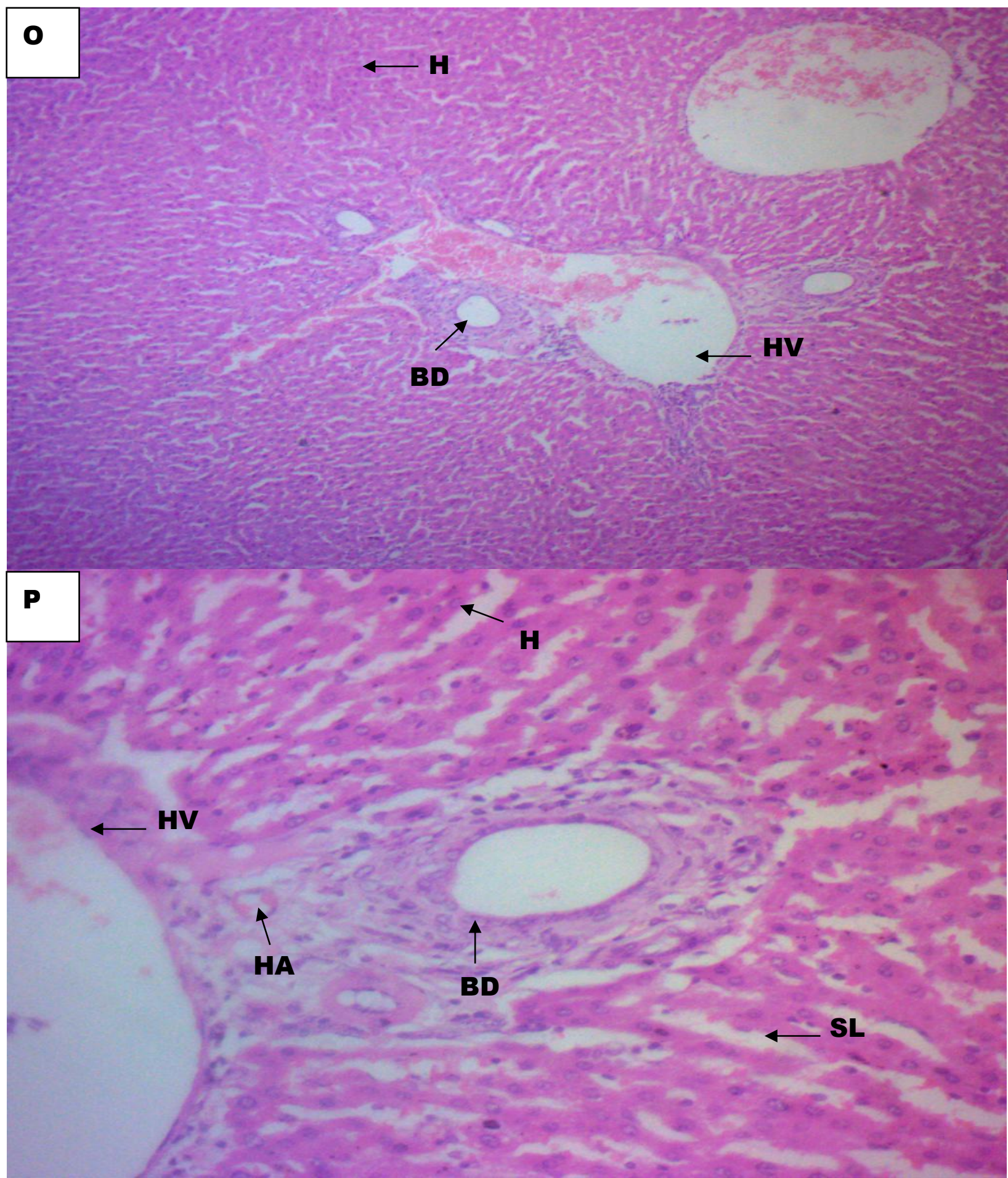

Figure 9: Photomicrographs of liver of Group 9 rats stained with $\mathrm{H}$ and $\mathrm{E}$ method at Mag. O (X100) and P (X400).

Keys: Portal Triad (PT), Hepatic Artery (HA), Hepatic Vein (HV), Bile duct (BD), Red Blood Cells (RBC), Hepatocytes (H), and Sinusoid Lining (SL) 


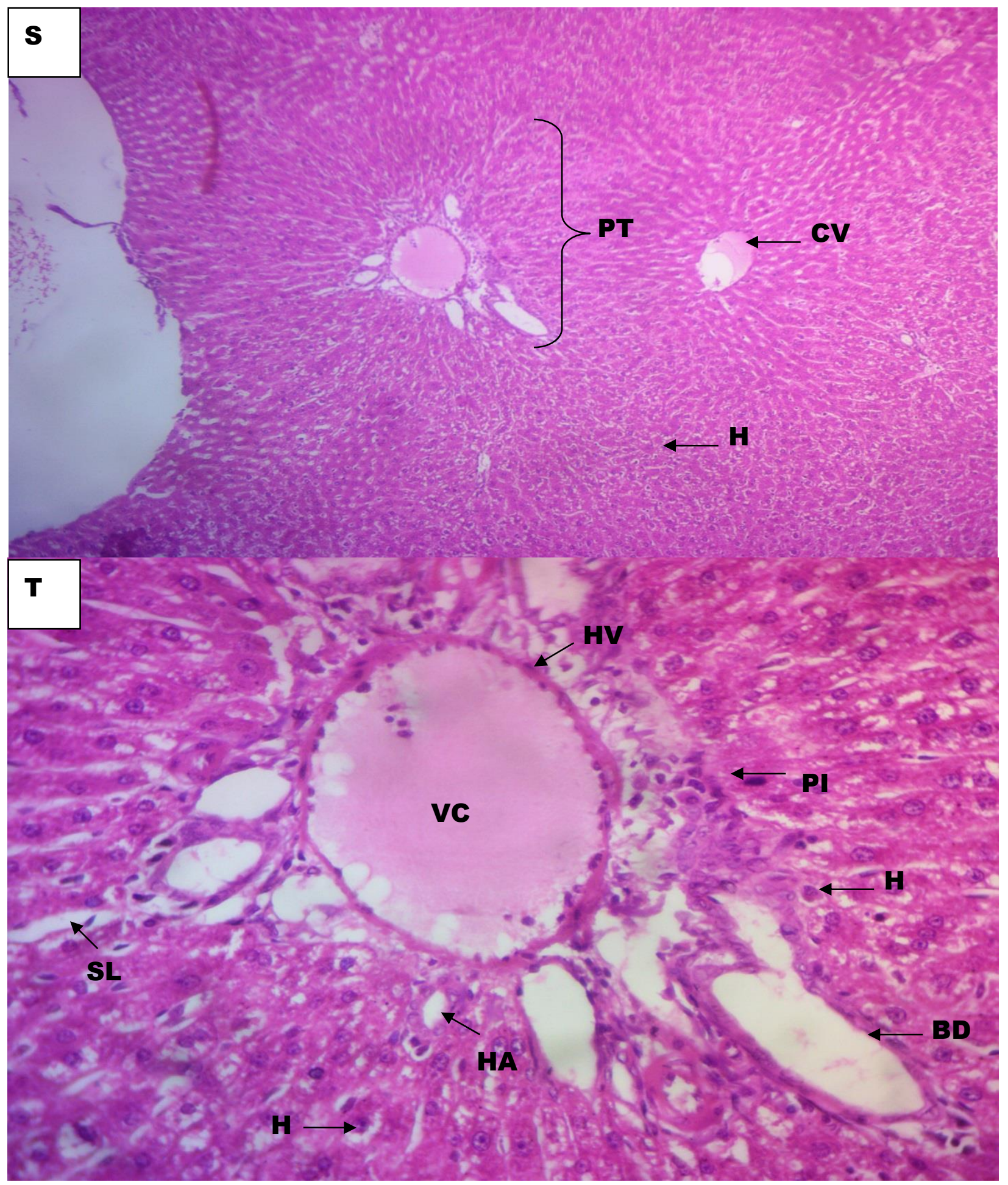

Figure 10: Photomicrographs of liver of Group 10 rats stained with $\mathrm{H}$ and $\mathrm{E}$ method at Mag. S(X100) and T(X400).

Keys: Portal Triad (PT), Hepatic Artery (HA), Hepatic Vein (HV), Bile duct (BD), Hepatocytes (H). Vascular congestion (VC), Periportal Inflammation (PI) and Sinusoid Lining (SL) 
Figure 1-10 presents the liver histopathology of the rats in various groups.

Figure 1 represents group 1(normal group) rats showing histologic section of the liver at magnification $\mathrm{A}(\mathrm{x} 100)$ and $\mathrm{B}(\mathrm{x} 400)$ which revealed normal cellular profile of hepatocytes, portal triad containing hepatic artery, vein and bile ducts, sinusoidal lining and central vein with well- defined collecting ducts all within normal cellular architecture without any form of abnormality.

Figure 2 shows Group 2 rats with histologic section of the Liver at magnification C(x100) and D(x400) revealing prominent vascular degeneration and congestion when compared to control group. It shows that the liver was moderately affected.

Figure 3 shows the histologic section of the liver of Group 3 rats at magnification $\mathrm{E}(\mathrm{x} 100)$ and $\mathrm{F}(\mathrm{x} 400)$ revealing prominent hyperplastic hyperplasia, vacuolation, vascular degeneration and congestion against background of pyknotic nuclei when compared to control group. It indicates severe damage.

Figure 4 shows the histologic section of the liver of Group 4 rats at magnification $G(x 100)$ and $H(x 400)$ revealing prominent hyperplastic hyperplasia, vacuolation, vascular degeneration and congestion against background of pyknotic nuclei when compared to control group. It indicates severe damage.

Figure 5 shows the histologic section of the liver of Group 5 rats at magnification I (x100) and J (x400) revealed prominent hepatocytes, portal triad and sinusoidal lining against the background of pyknotic nucleus when compared to control group. It shows they were not affected.

Figure 6 shows the histologic section of the liver of Group 6 rats at magnification J (x100) and K (x400) revealing reversible prominent hepatocytes, portal triad, sinusoidal lining periportal area of inflammation when compared to control group. This indicates that the liver was only slightly affected

Figure 7 shows the histologic section of the liver of Group 7 rats at magnification L (x100) and M (x400) revealing reversible prominent hepatocytes, portal triad and sinusoidal lining when compared to control group. It shows that they were not affected.

Figure 8 shows the histologic section of the liver of Group 8 rats at magnification N (x100) and O (x400) revealing hepatocytes, portal triad, vascular congestion and sinusoidal lining against the background of pyknotic nucleus when compared to control group.

They were not affected.

Figure 9 shows the histologic section of the liver of Group 9 rats at magnification P (x100) and Q (x400) revealing prominent hepatocytes, portal triad and sinusoidal lining against the background of pyknotic nucleus when compared to control group. They were not affected.

Figure 10 shows the histologic section of the liver of Group 10 rats at magnification R (x100) and S (x400) revealing hepatocytes, portal triad and sinusoidal lining against the background of pyknotic nucleus when compared to control group. The livers here were not affected.

Sodium arsenite has hepatotoxic potentials, due to the generation of reactive oxygen species $[14,15,16]$. The liver is known as the major organ of metabolism versatile in regulating the internal chemical environment. When sodium arsenite generates free radicals species, it causes an imbalance between the pro-oxidation and antioxidant homeostasis in the system [17,18]. The mechanism of damage of the liver by sodium arsenite includes; oxidative stress, enhanced inflammation and alteration in cellular methylation status [19,20]. ALT and AST activities are diagnostic indicators of liver damage [21,22]. An increase in their activities in sodium arsenite treated rats indicates possible hepatic membrane impairment leading to release of cytoplasmic contents into the circulation which can be confirmed on the hepatic histopathology alterations induced by arsenite toxication [23]. It was observed from this study that the animals treated with different duration of sodium 
arsenite suffered different degrees of liver dysfunction which was worst in the group that had longer duration of exposure (Group 3). This was evident in the significant increase in ALP, ALT and AST activities of the animals. This indicates that toxicity increases with longer duration of exposure [24]. The liver has regenerating potentials and the ability to recover from injury at a certain level with time [17], as this was observed in Group 2 animal having a moderate damage compared to Group 4 animals, even though they had the same duration of exposure. Whereas the Allium sativum and toxicant treated group (Group 6) only had a significant increase in ALP when compared to the control group (Group1). It was here observed that Allium sativum has more potential to lower liver enzymes activities especially ALT and AST [6] much more better than Gongronema latifolium, where significant increase was observed in ALP, ALT and AST activity in Gongronema latifolium and toxicant treated group (Group 5) when compared to the control group (Group 1). This increase in the liver enzymes was confirmed in the group treated with Gongronema latifolium only (Group8). So it can be inferred here that Gongronema latifolium has higher activities of ALP and AST. This is in line with previous researches [25, 26]. However, the combined extract and toxicant group (Group 7) showed significant reduction in AST only while other liver enzyme activities were same with the control group. Group 10 animals (combined extract only) had normal values of the parameter, but only slight increase in ALP which could be due to G. latifolium. This proves how potent the combined extract is, in tackling hepatotoxicity [3].

Histological examination of the liver revealed various forms of abnormality caused by the sodium arsenite toxicity. In this study it was observed that the severity of pathology depended on the duration of exposure to the sodium arsenite [27] as observed in Group 3 rats when compared to other group. The liver could recover to some extent from the injury caused by the sodium arsenite toxicity, as this was observed in Group 2 rats when compared to Group 4 rats where severe liver damage was observed. The damages observed in the liver cells could be attributed to reactive oxygen species (ROS) generated by arsenic toxicity which interact with membrane causing lipid peroxidation and therefore leading to cellular damage [1]. From this study it was observed that Gongronema latifolium and Allium sativum especially in combined form effectively reversed and confer protection on the hepatocytes against damage by the arsenite toxicity, this is believed to be as a result of their anti-oxidative, anti-peroxidative, as well as anti-mutagenic effect in which they synergistically possess $[5,6,827]$.

\subsection{Conclusion}

Allium sativum has been proven to be better than Gongronema latifolium when used in single forms while the combined form of the Allium sativum and Gongronema latifolium proved to be the best in ameliorating the hepatotoxicity induced by sodium arsenite.

\section{Acknowledgments}

This research was not supported by any organisation or funding body. However, the authors contributed collectively to carry out the research. 


\section{References}

1. Usoh, I. F., Akwa, N. E., Oyebadejo, S. A. and Ekpo, N. D. Protective potential of Gongronema latifolium and Allium sativum extracts against hyperlipidaemia and oxidative stress in albino Wistar rats with sodium arsenite induced toxicity. World Journal of Pharmacy and Pharmaceutical Sciences, 2019; 8 (12): 1-12.

2. Awal, M. Detection of arsenic in the food chain and animal samples and study of the preventive measure using the best cost effective agricultural product based spirulin against arseniasus in man and livestock . Annual Research Report (2006-2007), USDA-Bangladesh Collaborative Research, 2007.

3. Amrit, Rajesh, K. and Taiprect, K. Mechanism pertaining to arsenite toxicity. International Journal of Toxicolgy, 2011; 18 (2): 87-93.

4. Suzuki, T. and Tsukamoto, I. Arsenite induces apoptosis in hepatocytes through an enhancement of the activation of Jun-N-terminal kinase and p38 mitogen-activated protein kinase caused by partial hepatosectomy. Toxicology Letters, 2006; 165: 257-264.

5. Borek, C. Recent advances on the nutritional benefits accompanying the use of garlic as a supplement. New port Beach, 1998; 15-17.

6. Amagase, H..Clarifying the real bioactive constituent of garlic. Journal of Nutrition, 2006; 136:716s-725s.

7. Morebis, O., Fafunso, M. and Makinde, J. Membrane stabilizing activity: A possible mechanism of action for the anti-inflammatory property of Gongronema latifollium leaves in experimental arthritis. International Journal of Biomedical Health Science, 2005; 1 (2): 71-76.

8. Edet, E., Atangwho, I., Akpanabiatu, M., Edet, T., Uboh, F. and David-Oku, E. Effect of Gongronema latifolium leaf extract on some liver enzymes and protein levels in diabetic and non- diabetic rats. Journal of Pharmaceutical and Biomedical Sciences. 2011; 1 (5)104-107.

9. Nickson, R. T., Mc Arthur, M. J., Shrestha, B., Kyaw-Myint and Lowry, D. Arsenic and other drinking water quality issues, Muzaffargarh District, Pakistan. Applied Geochemistry, 2005; 20(1): 55-68.

10. Chen, S., Tsai, M., Wang, H., Yu, H. and Chang, L. Involvement of substance $P$ and neurogenic inflammation in arsenic- induced early vascular dysfunction. Toxicology of Science, 2007; 95:82-88.

11. Reitman, S. and Frankel, S. American Journal of Clinical Pathology, 1957; 28:56

12. GSCC/DGKC- Recommendation of the German Society of Clinical Chemists/ Deutsche Gesellschft fu Klinische. Quantitative in vitro determination of alkaline phosphatase (ALP) in serum and plasma. Journal of Clinical Chemistry and Clinical Biochemistry, 1972; 10:182.

13. Bancroft, J., stevens, A. and Turner, D. Theory and practice of histological techniques. $4^{\text {th }}$ Edition, Churchill Livingstone, New York, Edinburgh, London, Melbourne, San Francisco, Tokyo, 1996.

14. Kimura, A., Ishida, Y., Hayashi, T., Wada, T., Yakoyama, H.and Sugaya, T. Interferon-gamma plays protective roles in sodium arsenite- induced renal injury by up regulating intra renal multidrug resistanceassociated protein 1 expression. American Journal of Pathology, 2006; 169:1118-1128.

15. Rahman, M.., Chowdury, U., Mukherjee, S., Mondal, B., Paul, K., Lodh, D., Biswas, B., Chanda, C., Basu, G., Saha. K., Roy, S., Das, R., Palit, S.,Quamruzzaman, Q. and Chakraborti, D. Chronic arsenite toxicity in Bangladesh and West Bengal, India: a review and commentary. Journal of Toxicolgy and Clinical Toxicology, 2001; 39:683-700.

16. Nandi, D., Patra, D. and Swarup, D. Effect of cysteine, methionine, ascorbic acid and thiamine on arsenic induced oxidative stress and biochemical alterations in rats. Toxicology, 2005; 211:26-35. 
17. Santra, A., Marti, A., Das, S., Lahiri, S., Charkaborty, S. and Mazumder, D. Hepatic damage caused by chronic arsenic toxicity in experimental animals. Clinical Toxicology, 2000; 38(4) :395-405.

18. Vahter, M. Mechanism of arsenic transformation. Toxicology, 2002; 18:211-221.

19. Mazumder, D. Effect of chronic intake of arsenic- contaminated water on liver. Toxicology and Applied Pharmacology, 2005; 206 (2):169 -175.

20. Lindberg, A., Kumar, R., Goessler, W., Thirumaran, R., Gurzau, E. and Koppova. K Metabolism of low dose inorganic arsenic in central European population: influence of sex and genetic polymorphisms. Environmental Health Perspective, 2007; 115:1081-1086.

21. AGA. Technical review on the evaluation of liver chemistry tests. Gastroenterology. 2002; 123:1367-1384.

22. Christopher, E., Olivia, S., Wolfgang, S. Diagnostic criteria for acute liver failure due to Wilson disease. World Journal of Gastroenterology. 2007; 13:1711-1714.

23. Yousef, I. El- Demerdash, M. and Radwan, F. Sodium arsenite induced biochemical perturbations in rats: Ameliorating effect of curcumin. Food and Clinical Toxicology, 2008; 48:3506-3511.

24. Chowdhury, R., Dutta, A., Chaudhuri, S., Sharma, N., Giri, A., Chaudhuri, K. Food chemistry. Toxicology, 2008; 46 (2):740-751.

25. Nwangwu, C. Josiah, J., Abubakar, E., Ajeighe, O. and Akintola, A. Comparative effect of aqueous and ethanolic extracts of Gongronema latifollium on serum kidney and liver biomarkers of normal male rats. Asian Journal of Biological sciences, 2011; 4(7):540-547.

26. Sanjib, I. and Shattacharya, I. Medicinal plant and natural product in amelioration of arsenic toxicity: a short review. Pharmaceutical Biology, 2017; 55(1):847.

27. Islam, K., Haque, A., Karim, R., Fajol, A., Hossain, E., Salam, K., Ali, N., Saud, z., Rahman, M., Karim, R., Sultana, P., Hossain, M., Akhand, A., Mandal, A., Miyatka, H., Himeno, S. and Hossain. Dose-response relationship between arsenic exposure and the serum enzymes for liver function tests in individuals exposed to arsenic. Environmental Health, 2001; 10(64): 1-11. 